\title{
SISTEM PENJAMINAN MUTU INTERNAL DAN EKSTERNAL PADA LEMBAGA PENDIDIKAN TINGGI
}

\author{
Muhammad Fadhli \\ Program Studi Manajemen Pendidikan Islam, IAIN Lhokseumawe, Aceh, Indonesia \\ Email: fadhlikhan88@gmail.com
}

DOI: http://doi.org/10.33650/al-tanzim.v4i2. 1148

\begin{tabular}{l|l|l} 
Received: May 2020 & Accepted: August 2020 & Published: September 2020
\end{tabular}

\begin{abstract}
:
This study aims to portray internal and external quality assurance at higher education institutions, and the purpose of implementing quality assurance at educational institutions. In obtaining the data, this study used a library based qualitative approach by collecting data from books, journals, and articles. Based on the content analysis of the data, this study found that internal quality assurance includes: 1) policies and procedures for quality assurance; 2) approval, monitoring and periodic review of programs and awards; 3) student assessment; 4) quality assurance of teaching staff / lecturers; 5) resources student learning and support; 6) information systems; 7) public information. The external quality assurance includes: 1) use of procedures; 2 ) process development; 3) criteria for decisions; 4) processes in accordance with objectives; 5) reporting; 6) follow-up procedures; 7) periodic implementation reviews; and 8) system-wide analysis. The five objectives for quality assurance in educational institutions are improvement, innovation, communication, motivation, and control.
\end{abstract}

Keywords: internal quality assurance, external quality assurance, higher education institutions

\begin{abstract}
Abstrak:
Penelitian ini bertujuan untuk menggambarkan secara utuh dua hal utama dalam sistem penjaminan mutu pada lembaga pendidikan tingggi, yaitu; penjaminan mutu internal dan penjaminan mutu eksternal serta tujuan implementasi penjaminan mutu pada lembaga pendidikan. Dalam mendapatkan data penelitian ini digunakan pendekatan kualitatif jenis library research, dengan cara mengumpulkan data-data dari buku, jurnal dan artikel. Analisis datanya dilakukan dengan menggunakan content analysis. Hasil penelitian ditemukan bahwa: Pertama, penjaminan mutu internal meliputi: 1) kebijakan dan prosedur untuk penjaminan mutu; 2) persetujuan, pemantauan dan tinjauan berkala program dan penghargaan; 3) penilaian mahasiswa, 4) jaminan kualitas staf pengajar/dosen; 5) sumber belajar dan dukungan siswa; 6) sistem informasi; 7 ) informasi publik. Kedua, penjaminan mutu eksternal yaitu: 1) penggunaan prosedur; 2) pengembangan proses; 3) kriteria untuk keputusan; 4) proses sesuai dengan tujuan; 5) pelaporan; 6) prosedur tindak lanjut; 7) tinjauan pelaksanaan secara berkala; dan 8) analisis seluruh sistem. Ketiga, lima tujuan untuk penjaminan mutu pada lembaga pendidikan peningkatan, inovasi, komunikasi, motivasi dan pengawasan atau control.
\end{abstract}

Kata Kunci: penjaminan mutu internal, penjaminan mutu eksternal, lembaga pendidikan tinggi 


\section{PENDAHULUAN}

Sistem penjaminan mutu dalam lembaga pendidikan mutlak harus dijalankan dengan baik. Penjaminan mutu diperlukan sebagai alat untuk quality control/ pengawasan kualitas yang ada di lembaga pendidikan tersebut. Menghasilkan lembaga pendidikan yang bermutu merupakan tanggungjawab pengelola pendidikan mulai dari pemerintah pusat, daerah, sampai pada pendidik dan tenaga kependidikan. Masyarakat memiliki hak sekaligus memilki tanggung jawab terdapat hadirnya lembaga pendidikan yang berkulitas.

Lembaga pendidikan tinggi merupakan ujung tombak dalam peningkatan perkembagan masyarakat. Hal ini karena pendidikan tinggi memilki tri darma yaitu pengajaran, penelitian, dan pegabdian msayarakat. Transformasi lembaga pendidikan tinggi harus terus dilakukan untuk selalu menyesuaikan diri dengan perkembangan zaman.

Pendidikan tinggi berkualitas sangat penting bagi sebuah negara. Terutama bagi negera-negara berkembang. Pendidikan tinggi dapat memainkan peran penting dalam transformasi keseluruhan negara. Dintaranya; 1) pendidikan tinggi dapat dan harus memberikan kontribusi pada pembangunan ekonomi negara; 2) pendidikan tinggi dapat berkontribusi pada perkembangan demokrasi di negara sehingga dapat memberikan kontribusi pada pembaruan politik dan masyarakat; 3) pendidikan tinggi dapat memberikan kontribusi pada pembangunan dan penegasan identitas sebuah bangsa, 4) pendidikan tinggi dapat berkontribusi untuk memperkuat posisi dan reputasi negara di kancah internasional (Matei \& Iwinska, 2016).

Selanjutnya dalam laporan Bank Dunia menunjukkan pentingnya penjaminan mutu dan berimplikasi penting dalam beberapa hal yaitu: mobilitas peserta didik dan staf, penciptaan jenis baru lembaga pendidikan tinggi, kebebasan pengelolaam program akademik, penerapan pendidikan jarak jauh dan domain lain di mana pendidikan tinggi melampaui batas-batas standar nasional yang telah ditetapkan (Bernhard, 2012).

Menteri Riset, Teknologi, dan Pendidikan Tinggi Republik Indonesia (2016) menjelaskan; "mutu pendidikan tinggi adalah tingkat kesesuaian antara penyelenggaraan pendidikan tinggi dengan Standar Pendidikan Tinggi yang terdiri atas Standar Nasional Pendidikan Tinggi dan Standar Pendidikan Tinggi yang ditetapkan oleh Perguruan Tinggi".

Jumlah perguruan tinggi Indonesia dapat dikatakan cukup besar. Berdasarkan data yang dimilki oleh Kementerian Riset, Tekonologi, dan Pendidikan Tinggi Indonesia memiliki jumlah perguruan tinggi sebanyak 4.739 perguruan tinggi, 279.480 orang dosen, dan 5.904.857 orang mahasiswa. Untuk lebih jelasnya dapat dilihat pada tabel berikut: 
Tabel 1 : Data Perguruan Tinggi, Dosen, dan Mahasiswa

\begin{tabular}{rlccccc}
\hline NO & \multicolumn{1}{c}{ PT } & Jumlah & Dosen & Jumlah & Mahasiswa & Jumlah \\
\hline 1 & Akademi & 1.053 & S1 & 30.612 & Perempuan & 3.180 .028 \\
\hline 2 & Politeknik & 289 & S2 & 206.300 & Laki-Laki & 2.724 .829 \\
\hline 3 & Sekolah Tinggi & 2.553 & S3 & 42.568 & & \\
\hline 4 & Institut & 224 & & & & \\
\hline 5 & Universitas & 599 & & & & \\
\hline 6 & Akad. Komunitas & 21 & & & & \\
\hline & JUMLAH & 4.739 & 279.480 & & \\
\hline
\end{tabular}

Sumber : https:// forlap.ristekdikti.go.id/

Besarnya jumlah perguruan tinggi di Indonesia tersebut belum tentu berkorelasi terhadap peningkatan kualitas sumberdaya manusia Indonesia. Karena perguruan tinggi tersebut sebagian besar belum memilki kualitas yang baik.

Tabel 2 : Hasil Akreditasi Prodi/PT (Persen A, B, C)

\begin{tabular}{cccc}
\hline \multirow{2}{*}{ No } & \multicolumn{3}{c}{ Akreditasi } \\
\cline { 2 - 4 } & Nilai Akreditasi & PT & Prodi \\
\hline 1 & $\mathrm{~A}$ & 81 & 3,501 \\
\hline 2 & $\mathrm{~B}$ & 751 & 11,401 \\
\hline 3 & $\mathrm{C}$ & 1,191 & 5,401 \\
\hline \multicolumn{4}{c}{}
\end{tabular}

Berdasarkan data-data pada tabel 2 di atas, dapat dipahami bahwa pendidikan tinggi di Indonesia masih belum dapat dikatakan berkualitas. Dar hasil penjaminan mutu eksternal yang dilakukan oleh Badan Akreditasi Nasional Perguruan Tinggi (BAN-PT), banyak lembaga pendidikan tinggi yang masih terakreditasi dengan nilai C. Oleh karena itu, lembaga pendidikan tinggi perlu melakukan pembenahan untuk terus meningkatkan mutunya.

Selanjutnya, berdasarkan data yang dikeluarkan oleh lembaga pemeringkat pendidikan tinggu dunia seperti: Times Higher Education (THE) dan webometrics perguruan tinggi indonesia tidak ada yang berada di level 100 besar dunia bahkan Asia. Universitas Indonesia (UI) hanya mampu menempati peringkat 800an dan UI merupakan perguruan tinggi terbaik di Indonesia. Dapat dibayangkan level perguruan tinggi lainnya yang berada di luar pula jawa termasuk PTKI.

Dengan pertumbuhan jumlah perguruan tinggi dan jumlah mahasiswa yang semakin meningkat seiring dengan tuntutan untuk menjaga dan meningkatkan mutu pendidikan tinggi yang juga makin besar, maka diperlukan kebijakan-kebijakan yang konkrit dan mendukung dari para pemangku kepentingan. Pendidikan tinggi di negara-negara maju memilki sistem penjaminan mutu dengan model dan strategi tersendiri. Namun, pada umumnya sistem penjaminan mutu mereka terdiri dari penjaminan mutu internal dan eksternal. Perguruan tinggi di Indonesia memiliki dua kebijakan penjaminan mutu, yaitu penjaminan mutu internal dan penjaminan mutu eksternal. 
Sistem penjaminan mutu yang efektif di lembaga pendidikan akan memberikan dampak positif baik secara langsung maupun tidak langsung. Sistem penjaminan mutu yang umumnya dilaksanakan melalui proses audit yang ketat memiliki dampak langsung dan dampak tidak langsung. Dampak langsungnya antara lain transparansi, pembelajaran efektif, peningkatan status, dan integrasi sosial lembaga, sementara dampak tidak langsung hanya muncul yaitu, motivasi, hubungan baik di kalangan organisasi dan lainnya. Selanjutnya Haapakorpi menyatakan struktur dan manajemen organisasi, budaya dan disiplin individu memberikan pengaruh terhadap hasil penjaminan mutu (Haapakorpi, 2011).

Penjaminan mutu yang efektif merupakan tujuan dari semua lembaga pendidikan berkualitas. Penjaminan mutu internal berfungsi dalam menunjang target-target akademik, seperti kesesuaian klasifikasi gelar akademik dan validitas informasi tentang mutu akademik. Sementara itu, penjaminan mutu eksternal dirancang untuk memastikan lembaga telah menerapkan proses penjaminan mutu internal yang efektif. Penjaminan mutu eksternal juga berfungsi membantu mengarahkan persepsi publik dan akademik tentang mutu suatu lembaga pendidikan (Dill, 2010).

Dalam dunia pendidikan, pembuat kebijakan sebagai penyokong dana, memiliki tanggung jawab untuk berinvestasi dan memastikan investasi yang mereka lakukan dengan benar. Oleh karena itu, lembaga penjaminan mutu perlu dibuat oleh pemerintah. Hal ini juga merupakan wujud tanggungjawab pemerintah kepada masyarakat sebagai upaya peningkatan kualitas pembangunan sumber daya manusia suatu bangsa. Sistem Penjaminan Mutu Pendidikan Tinggi adalah kegiatan sistemik untuk meningkatkan mutu pendidikan tinggi secara berencana dan berkelanjutan. Indonesia mengenal dua sistem dalam proses penjaminan mutunya, yaitu penjaminan mutu internal dan eksternal. Riset ini bertujuan memberikan gambaran sebagai panduan kebijakan dalam penjaminan mutu (internal dan ekternal) guna pencapaian mutu lembaga pendidikan tinggi yang baik.

\section{METODE PENELITIAN}

Metode dan jenis pengumpulan data dalam penelitian ini adalah studi pustaka (library reseach) dengan mengumpulkan buku-buku, jurnal, dan hasil penelitian terdahulu yang mendukung tema penelitian, di antaranya literatur tentang manajemen mutu, penjaminan mutu internal dan penjaminan mutu eksternal. Proses penelitian ini dimulai dengan tahapan sebagai berikut: mengidentifikasi dan menemukan informasi yang relevan dengan tema penjaminan mutu, kemudian menganalisis hasil temuan, dan kemudian mengembangkan dan mengekspresikannya menjadi temuan baru terkait dengan penjaminan mutu pada lembaga pendidikan tinggi (Masrukhin, 2015).

\section{HASIL DAN PEMBAHASAN}

Penjaminan Mutu Internal

Sistem penjaminan mutu internal merupakan proses penjaminan mutu yang dilakukan secara mandiri oleh lembaga pendidikan. Penjaminan mutu internal membantu persiapan lembaga pendidikan untuk menjalani proses 
penjaminan mutu secara eksternal. Oleh karena itu penjaminan mutu internal harus mampu membuat program-program yang sesuai dengan tujuan pencapaian mutu yang baik.

Kementerian Riset, Tekonologi, dan Pendidikan Tinggi menjelaskan bahwa Sistem Penjaminan Mutu Internal (SPMI) adalah kegiatan sistemik penjaminan mutu pendidikan tinggi oleh setiap perguruan tinggi secara otonom untuk mengendalikan dan meningkatkan penyelenggaraan pendidikan tinggi secara berencana dan berkelanjutan.

Hasil penelitian baru-baru ini memperlihatkan bahwa ada tren yang kuat disebabkan oleh diberlakukannya sistem penjaminan mutu di pendidikan tinggi di Eropa terhadap penguatan mutu pendidikan. "Audit mutu" atau "audit kelembagaan" adalah sistem dan kebijakan yang paling banyak digunakan sebagai instrumen penjaminan mutu. Kajian ini juga menemukan bahwa refleksi terhadap peningkatan kualitas yang dihasilkan dari dalam lembaga (internal) adalah hal yang paling penting dicapai daripada dorongan lembaga eksternal (Corengia, et al., 2014).

Selain itu, lembaga-lembaga pendidikan tinggi di Eropa membuat standar dan pedoman dalam upaya penjaminan mutu internal. Lembaga pendidikan akan dikatakan memilki mutu jika telah bahkan melampaui standar dan pedoman tersebut. Standar dan pedoman ini merupakan satu kesatuan yang harus mampu dipenuhi oleh setiap lembaga pendidikan tinggi Eropa. Untuk lebih jelaskan dapat diuraikan sebagai berikut:

1. Kebijakan dan prosedur untuk penjaminan mutu. Langkah awal sebuah lembaga pendidikan dalam upaya penjaminan mutu adalah membuat kebijakan dan prosedur langkah-langkah penjaminan mutu yang bertujuan untuk menigkatkan mutu. Kebijakan harus mampu menciptakan budaya mutu dan kebijakan harus bersifat berkelanjutan/ terus menerus. Dalam hal ini penting bagi lembaga melibatkan seluruh stakeholdernya.

2. Persetujuan, pemantauan dan tinjauan berkala atas program dan penghargaan. Hal ini bertujuan agar lembaga memiliki mekanisme secara formal (SOP) adalah upaya pembuatan program-program di lembaganya serta cara memberikan reward atas keberhasilan program-program tersebut.

3. Penilaian mahasiswa. Proses evaluasi peserta didik harus dilakukan dengan transparan, artinya peserta didik harus diberitahu sebelumnya tentang kriteria, peraturan, dan prosedur yang akan menjadi bahan penilaian.

4. penjaminan mutu tenaga pendidik. Tenaga pendidikan merupakan faktor utama dalam lembaga pendidikan, oleh karena itu lembaga pendidikan harus mampu menerapkan manajemen SDM yang berkelanjutan untuk upaya pengembangan-pengembagan tenaga pendidik. Memberikan motivasi dengan berbagai cara seperti kompensasi yang memadai, pembinanaan dan lain sebagainya.

5. Sumber belajar dan dukungan siswa. Sumber belajar harus benar-benar dipastikan ketersediannya sebagai komitmen lembaga untuk pengembangan dan peningkatan kompetensi lulusan. Setiap programprogram yang ditawarkan harus terlebih dahulu dipersiapkan ketersediaan sumber belajarnya. 
6. Sistem informasi. Penting bagi lembaga pendidikan untuk membuat sistem informasi sebagai alat untuk mengumpulkan, menganalisis, dan kemudian menggunakan informasi untuk pengelolaan program studi dan kegiatan lainnya yang efektif.

7. Informasi publik. Memberikan informasi yang sesuai dan relevan kepada publik tentang program yang dimilki dan ditawarkan merupakan tanggungjawab dan kewajiban lembaga pendidikan (ENQA, 2009).

Kemudian setelah standar dan pedoman ditetapkan, perlu dibuat mekanisme penjaminan mutu internal. Al-Alawi et al., (2009) menemukan mekanisme penjaminan mutu internal, yaitu: 1) membentuk komite penjaminan mutu, seperti Lembaga Penjaminan Mutu; 2) mengundang konsultan penjaminan mutu; 3) menilai umpan balik; 4) mengembangkan software untuk pengarsipan dokumen jaminan mutu; 5) menetapkan sistem pengarsipan untuk dokumentasi penjaminan mutu; 6) mempersiapkan templet untuk spesifikasi program, spesifikasi mata kuliah, dan ujian akhir.

Direktorat Penjaminan Mutu Kemenristekdikti telah membuat pedoman penjaminan mutu internal di lembaga pendidikan tinggi. Beberapa prinsip yang harus dilakukan dalam upaya penjaminan mutu internal sebagai berikut; pertama, Otonom. SPMI dikembangkan dan diimplementasikan secara otonom atau mandiri oleh setiap perguruan tinggi, baik pada aras Unit Pengelola Program Studi (Jurusan, Departemen, Sekolah, atau bentuk lain) maupun pada aras perguruan tinggi. Kedua, terstandar. SPMI menggunakan Standar Dikti yang terdiri atas SN Dikti yang ditetapkan oleh Menteri dan Standar Dikti yang ditetapkan oleh setiap perguruan tinggi. Ketiga, Akurasi. SPMI menggunakan data dan informasi yang akurat pada PD Dikti. Keempat, terencana dan Berkelanjutan. SPMI diimplementasikan dengan menggunakan 5 (lima) langkah penjaminan mutu, yaitu PPEPP Standar Dikti yang membentuk suatu siklus. Kelima, terdokumentasi. Setiap langkah PPEPP dalam SPMI harus ditulis dalam suatu dokumen, dan didokumentasikan secara sistematis.

Pada prinsipnya penjaminan mutu harus dilakukan dengan sungguhsungguh. Dukungan dari berbagai pihak merupakan hal yang akan sangat membantu lembaga pendidikan dalam pelaksanaannya. Penjaminan mutu internal harus dilakukan secara berkala dan berkelanjutan untuk mencapai budaya mutu pada lembaga pendidikan.

\section{Penjaminan Mutu Eksternal}

Untuk mendapatkan kriteria kualitas, maka suatu lembaga pendidikan perlu mendapatkan pengakuan sekaligus legalitas dari lembaga lainnya. Penjaminan mutu eksternal penting untuk melihat capaian lembaga pendidikan dalam memenuhi standar yang telah ditentukan. Penjaminan mutu eksternal diperlukan untuk sebagai pertanggungjawaban dan alat publikasi kepada stakeholder lembaga pendidikan.

Sistem Penjaminan Mutu Eksternal (SPME) merupakan kegiatan penilaian melalui akreditasi untuk menentukan kelayakan dan tingkat pencapaian mutu program studi dan perguruan tinggi" (Riset \& Pendidikan Tinggi, 2016). 
Cheung \& Tsui (2010) mendefenisikan penjaminan mutu eksternal sebagai a process of sharing experience and benchmarking against best practices Penjaminan mutu eksternal merupakan sebuah rangkaian proses berbagi pengalaman dan benchmark terhadap praktik pendidikan yang terbaik. Tujuannya adalah untuk membantu, membuat rekomendasi, dan memberikan saran untuk mendapatkan keunggulan, relevansi, dan keragaman.

Selain penjaminan mutu internal, pendidikan tinggi Eropa juga membuat 8 (delapan) standar dalam penjaminan kualitas eksternal. Kedelapan standar ini harus dipenuhi oleh pendidikan tinggi secara keseluruhan dan terintegarasi pada tiap standarnya. Untuk lebih jelas tentang masing-masing standar dapat diuraikan sebagai berikut;

Pertama, penggunaan prosedur penjaminan kualitas internal. Penjaminan mutu eksternal juga melihat dan mempertimbangkan proses penjaminan mutu yang dilaksanakan oleh internal lembaga. Untuk itu perlu sinergisitas antara penjaminan mutu internal dengan eksternal. Kedua, pengembangan proses penjaminan mutu eksternal. Proses penjamninan mutu eksternal harus mengembangkan prosedur yang akan dilaksanakan kemudian mempublikasikannya/ memberikan informasi kepada lembaga pendidikan. Proses pengembangan prosesdur (termasuk instrumen) baiknya melibatkan lembaga pendidikan. Ketiga, kriteria untuk keputusan. Maksudnya kriteriakriteria yang akan menjadi bahan keputusan hasil akreditasi eksternal nantinya harus diberikan informasinya kepada lembaga pendidikan. Kriteria ini juga harus diimplemetasikan secara konsisten. Keempat, Proses sesuai dengan tujuan. Penjaminan mutu eksternal juga harus sesuai dengan tujuan. Setiap proses didesain untuk mencapai tujuan yaitu peningkatan mutu pendidikan. Kelima, pelaporan. Pemberian laporan harus bersifat sesederhana mungkin agar mudah difahami. Seluruh hasil penjaminan mutu eksternal baik itu rekomendasi, pujian dan lain sebagainya harus ditampilkan untuk bahan evaluasi. Keenam, prosedur tindak lanjut. Penjaminan mutu yang bersifat rekomendasi untuk tindakan perbaikan, harus memiliki prosedur tindak lanjut yang telah ditentukan yang dilaksanakan secara konsisten. Ketujuh, tinjauan berkala. Proses penjaminan mutu eksternal baik untuk institusi maupun program studi harus dilaksanakan secara berkala, Kedelapan, analisis seluruh sistem: Lembaga penjaminan mutu eksternal harus menghasilkan ringkasan laporan yang menggambarkan dan menganalisis temuan umum dari analisis data, evaluasi, penilaian, dan lainnya(ENQA, 2009).

Demi kelancaran prosedur, akuntabilitas dan integritas lembaga penjamin mutu eksternal, maka orang-orang yang akan melakukan prosesnya (asesor) harus memiliki kompetensi. Cheung (2015) menjabarkan kompetensi penting yang harus dimiliki praktisi penjaminan mutu eksternal. Kompetensi tersebut antara lain: memiliki profesional, mampu memeriksa dengan sistematis, mampu menganalisis situasi, kemapuan manajemen, reflektif, dan memiliki kompetensi interpersonal.

Sistem penjaminan mutu pendidikan tinggi di Indonesia sudah diatur dalam Undang-Undang Nomor 12 tahun 2012 tentang Pendidikan Tinggi. Dalam undangundang ini terdapat aturan tentang penjaminan mutu, standar 
pendidikan tinggi, dan akreditasi. Sistem penjaminan mutu eksternal direncanakan, dievaluasi, dilaksanakan, dikendalikan, dan dikembangkan oleh BANPT dan/atau LAM melalui akreditasi sesuai dengan kewenangan masingmasing. Pelaksanaannya mengacu pada Standar Nasional Pendidikan Tinggi (SN Dikti).

\section{Kontribusi Penjaminan Mutu terhadap Peningkatan Mutu}

Peningkatan mutu merupakan isu utama yang sering menjadi bahan diskusi baik secara ilmiah maupun non ilmiah di lembaga pendidikan. Lembaga pendidikan yang baik akan terus melakukan inovasi-inovasi agar upaya peningkatan mutu dapat diraih. Inovasi berkelanjutan dibutuhkan karena defenisi mutu yang disepakati secara umum oleh ilmuan/akademisi maupun praktisi belum ditemukan.

Ishikawa memberi definisi mutu dalam dua aspek, yaitu kualitas sejalan dengan kepuasan pelanggan dan kualitas juga mencakup kualitas orang, proses, dan setiap aspek lain dari organisasi (Goetsch \& Davis, 2014). Sejalan dengan Ishikawa, Oakland (2014) mendefinisikan quality is meeting the customer requirements, and this is not restricted to the functional characteristics of the product or service. Kualitas memenuhi persyaratan pelanggan, dan ini tidak terbatas pada karakteristik fungsional dari produk atau layanan.

Sementara itu Goetsch \& Davis (2014) menjelaskan mutu adalah keadaan dinamis yang terkait dengan produk, layanan, orang, proses, dan lingkungan yang memenuhi atau melampaui harapan dan membantu menghasilkan keunggulan.

Berdasarkan ulasan berbagai defenisi diatas terbukti upaya memberikan defenisi dalam mutu terutama mutu pendidikan bukan hal yang mudah. Harvey \& Green sebagaimana dikutip oleh Goldenberg (2018) memberikan lima kategori yang mengelompokkan berbagai cara berfikir tentang mutu, yaitu; pertama, mutu sebagai sesuatu yang luar biasa; kedua, mutu sebagai kesempurnaan atau konsistensi yang berfokus pada proses dan tujuan; ketiga, mutu sebagai menyesuaikan dengan menyatakan tujuan; keempat, mutu sebagai nilai untuk uang; dan kelima, mutu sebagai transformasi/ perubahan. Untuk lebih jelasnya diuraikan sebagai berikut;

1. Mutu sebagai sesuatu yang luar biasa. Lembaga pendidikan yang berumutu harus menunjukkan karakter-karakter yang luar biasa sehingga mampu menciptakan prestasi.

2. Kualitas sebagai kesempurnaan atau konsistensi. Lembaga pendidikan bermutu harus mampu menunjukkan kesempurnaan (hampir tanpa cacat) dan harus dilakukan secara terus menerus memperbaiki demi mencapai kesempurnaan.

3. Mutu menyesuaikan dengan tujuan. Setiap lembaga pendidikan harus memiliki tujuan yang disusun sesuai dengan visi dan misi lembaga.

4. Mutu sebagai nilai untuk uang (keuntungan). Sebagai lembaga non profit tentunya mutu lembaga pendidikan tidak diukur dengan keuntungan berupa materi namun keuntungan diukur berdasarkan prestasi-prestasi yang diperoleh lembaga tersebut. 
5. Kualitas sebagai transformasi. Lembaga pendidikan harus terus berubah/ transformasi guna menyesuaikan dengan perkembangan zaman serta perkembangan teknologi dan informasi. Mendapatkan pelayanan sesuai dengan perkembangan merupakan hak peserta ddik guna persiapan untuk menghadapi perkembangan zaman di masa depan.

Dalam upaya penjaminan mutu, terdapat empat prinsip untuk sistem penjaminan mutu: 1) adanya lembaga koordinasi untuk membuat skema penjaminan mutu (LPM); 2) penyerahan laporan evaluasi diri/ oleh unit yang akan dievaluasi; 3) asesmen lapangan oleh lembaga akreditasi dan 4) laporan kepada publik tentang hasil evaluasi. Ini adalah model yang cukup umum yang dapat ditemukan dalam berbagai variasi di seluruh dunia (Bernhard, 2012). Untuk mendapatkan mutu pendidikan tinggi, lembaga pendidikan perlu melakukan prosedur yang sesuai dengan mekanisme.

Xiao \& Zhang, (2017) menguraikan mekanisme sistem penjaminan mutu yang dilakukan oleh pendidikan tinggi di Cina. Pertama, pendidikan tinggi memberikan kesempatan bagi calon mahasiswa yang memiliki bakat instimewa (berprestasi), memberi penekanan besar pada pendaftaran kandidat yang berbakat, memberikan kriteria tinggi untuk input calon mahassiswa baru, dan mewajibkan pendaftar menjalani ujian tambahan.

Kedua, mendapat dukungan penuh dari pemerintah baik pusat maupun daerah baik secara finansial maupun politik melalui kebijakan-kebijakan yang mendukung pendidikan tinggi, memberikan dan pendidikan yang cukup untuk menjadikan pendidikan tinggi berkelas dunia, memberikan fasilitas seperti pengadaan laboratorium canggih serta memberikan kompensasi yang bagi civitas akademika.

Ketiga, memberikan kebebasan dalam desain dan pengembangan kurikulum, metode pembelajaran dan evaluasi/ ujian, yang disesuaikan dengan kebutuhan mahasiswa. Menyediakan tempat magang yang baik dan memberikan kesempatan kepada mahasiswa siswa untuk berpartisipasi terlibat proses pendidikan, seperti evaluasi mutu pengajaran, pembelian buku profesional, dan evaluasi fasilitas pengajaran. Bagian penting lainnya, selain melakukan penjaminan mutu internal pendidikan tinggi juga perlu melakukan penjaminan mutu secara eksternal melalui lembaga-lembaga lainnya yang berwenang. Mekanisme penjaminan mutu memiliki tujuan yang tentunya memberikan efek positif terhadap mutu lembaga pendidikan itu sendiri. Untuk itu diperlukan tahapan-tahapan dalam pelaksanaannya.

Hasil penelitian juga menunjukkan beberapa mekanisme penjaminan pada layanan akademik dan layanan administrasi. Mekanisme penjaminan mutu untuk sektor akademik berkaitan dengan mata kuliah, mahasiswa, dan staf akademik. Berikut ini mekanisme yang harus dijalankan oleh lembaga pendidikan dalam prose penjaminan mutu, antara lain: evaluasi kurikulum dan tenaga pendidik, manajemen mutu terpadu, program pelatihan dan praktek akademik (PPL), membuat pusat e-learning, memberikan perhatian khusus pada peserta didik yang memiliki kesulitan (Alawi et al., 2009). 
Penjaminan mutu yang baik harus dilakukan secara sistematis. Maksudnya harus sesuai dengan kaidah-kaidah yang telah disepakati dan efektif. Oleh karena itu, diperlukan tahapan/ fase-fase yang baik. Jeliazkova dan Westerheijden mengembangkan sebuah model tahapan dalam penjaminan mutu (dapat dilihat pada Tabel 3). Model ini menunjukkan empat fase dalam mengembangkan sistem penjaminan mutu yang disesuaikan dengan permasalahan yang biasa dialami oleh pendidikan tinggi (Bernhard, 2012).

Masing-masing fase ini memiliki fungsi berbeda untuk penjaminan mutu, misalnya dalam proses akreditasi mampu memastikan tingkat standar mutu, tetapi jauh lebih cocok untuk merangsang peningkatan berkelanjutan di atas standar yang telah ditetapkan saat melihat fase 1 dari model ini. Tantangan baru untuk pendidikan tinggi adalah untuk mencari tahu langkah-langkah dan prosedur yang sesuai untuk memberikan transparansi kepada pemangku kepentingan masing-masing, seperti mahasiswa, masyarakat dan pemerintah. Karena itu, semua sistem pendidikan tinggi memerlukan sistem evaluasi eksternal yang tepat.

\section{Tabel 3 : Fase dalam Sistem Penjaminan Mutu}

\begin{tabular}{|c|c|c|c|}
\hline 1. Masalah & $\begin{array}{l}\text { 2. Peran jaminan } \\
\text { kualitas }\end{array}$ & 3. Basis informasi & $\begin{array}{l}\text { 4. Sifat evaluasi } \\
\text { eksternal }\end{array}$ \\
\hline $\begin{array}{l}\text { Fase 1: Keraguan } \\
\text { serius tentang } \\
\text { standar } \\
\text { pendidikan }\end{array}$ & $\begin{array}{l}\text { Mengidentifikasi } \\
\text { program } \\
\text { pendidikan di } \\
\text { bawah standar }\end{array}$ & $\begin{array}{l}\text { Laporan } \\
\text { deskriptif. } \\
\text { Indikator kinerja. }\end{array}$ & $\begin{array}{l}\text { Sumatif/hasil; } \\
\text { akreditasi, } \\
\text { pemeriksaan } \\
\text { standar. } \\
\text { Laporkan ke } \\
\text { negara. }\end{array}$ \\
\hline $\begin{array}{l}\text { Fase 2: Keraguan } \\
\text { tentang efisiensi } \\
\text { sistem dan / atau } \\
\text { institusi } \\
\text { pendidikan tinggi }\end{array}$ & $\begin{array}{l}\text { a) Akuntabilitas } \\
\text { publik } \\
\text { b) Menciptakan } \\
\text { kesadaran mutu } \\
\text { di lembaga. }\end{array}$ & $\begin{array}{l}\text { Laporan } \\
\text { deskriptif } \\
\text { meliputi: } \\
\text { a) kinerja, } \\
\text { b) prosedur }\end{array}$ & $\begin{array}{l}\text { Rangking institusi. } \\
\text { Satu laporan ke } \\
\text { negara dan institusi. } \\
\text { mengidentifikasi } \\
\text { praktik yang baik. }\end{array}$ \\
\hline $\begin{array}{l}\text { Fase 3: Keraguan } \\
\text { tentang kapasitas } \\
\text { inovasi dan } \\
\text { kapasitas } \\
\text { penjaminan mutu } \\
\text { lembaga }\end{array}$ & $\begin{array}{l}\text { Menstimulasi } \\
\text { kemamuan } \\
\text { pengaturan } \\
\text { lembaga secara } \\
\text { mandiri. } \\
\text { Akuntabilitas } \\
\text { publik. }\end{array}$ & $\begin{array}{l}\text { Laporan evaluasi } \\
\text { diri tentang: } \\
\text { a) prosedur, } \\
\text { b) kinerja }\end{array}$ & $\begin{array}{l}\text { Laporan audit ke: } \\
\text { - institusi } \\
\text { - negara }\end{array}$ \\
\hline $\begin{array}{l}\text { Fase 4: Perlu } \\
\text { menstimulasi } \\
\text { mutu yang } \\
\text { berkelanjutan } \\
\text { dalam berbagai } \\
\text { institusi }\end{array}$ & $\begin{array}{l}\text { Membagi antara: } \\
\text { - peningkatan } \\
\text { berdasarkan } \\
\text { kemandirian; } \\
\text { - akuntabilitas } \\
\text { publik. }\end{array}$ & $\begin{array}{l}\text { Membagi antara: } \\
\text { - laporan evaluasi } \\
\text { diri tentang } \\
\text { proses dan } \\
\text { strategi } \\
\text { berdasarkan } \\
\text { SWOT dan } \\
\text { benchmarking; } \\
\text { - pelaporan } \\
\text { mandiri tentang } \\
\text { indikator kinerja }\end{array}$ & $\begin{array}{l}\text { Membagi antara: } \\
\text { - laporan audit ke } \\
\text { lembaga; } \\
\text { - memverifikasi } \\
\text { data yang akan } \\
\text { dimasukkan dalam } \\
\text { database publik }\end{array}$ \\
\hline
\end{tabular}




\begin{tabular}{|c|c|c|c|}
\hline $\begin{array}{l}\text { Tantangan baru: } \\
\text { Menurunnya } \\
\text { transparansi di } \\
\text { seluruh sistem } \\
\text { pendidikan tinggi. }\end{array}$ & $\begin{array}{l}\text { Peraturan pasar, } \\
\text { yaitu } \\
\text { menginformasikan } \\
\text { kepada klien } \\
\text { (pelajar, } \\
\text { pemerintah). }\end{array}$ & $\begin{array}{l}\text { Indikator kinerja } \\
\text { tentang produk } \\
\text { (pengetahuan dan } \\
\text { keterampilan } \\
\text { lulusan). }\end{array}$ & $\begin{array}{l}\text { Publikasi indikator } \\
\text { kinerja yang } \\
\text { komparatif. } \\
\text { Tes standar } \\
\text { lulusan? }\end{array}$ \\
\hline
\end{tabular}

Tahapan-tahapan dalam proses penjaminan mutu tersebut tentunya memiliki tujuan. Setidaknya terdapat lima tujuan untuk penjaminan mutu pada lembaga pendidikan, yaitu: improvement, innovation, communication, motivation and control (Rosa, 2014). Kelima tujuan ini tentunya akan menjadi acuan dalam proses penajminan mutu lembaga pendidikan tinggi. Untuk lebih jelas tentang masing-masing tujuan tersebut, maka diuraikan sebagai berikut:

Improvement. Tujuan yang pertama dari penjaminan mutu adalah untuk peningkatan lembaga pendidikan. Tujuan ini mencerminkan bahwa penjaminan mutu menjadi salah satu cara agar lembaga pendidikan mengalami peningkatan dan perkembangan. Oleh karena itu sistem penjaminan mutu harus mengarah pada upaya-upaya peningkatan mutu khususnya pada bidang-bidang akademik atau yang berkenaan langsung dengan proses pembelajaran.

Innovation. Kemudian tujuan yang kedua adalah sebagai bahan berinovasi. Inovasi berbeda dengan perbaikan. Inovasi bertujuan mencari sesuatu atau menemukan hal baru. Penjaminan mutu berperan dalam menciptakan inovasi-inovasi baru dalam lembaga pendidikan, karena mutu yang baik harus terus berkembang sesuai perkembangan zaman. Perbaikan proses dan metodologi pembelajaran, sistem informasi, manajemen serta penelitian harus terus dilakukan guna menjadi lebih baik dan up to date.

Communication. Selanjutnya tujuan penjaminan mutu adalah sebagai alat komunikasi. Komunikasi disini maksudnya sebagai pemberi informasi kepada para civitas akademika tentang apa yang sudah ada dan hal apa yang perlu ditingkatkan. Selain itu tujuan ini untuk memberikan informasi kepada publik dan stakeholder lainnya tentang capaian yang diraih oleh lembaga pendidikan.

Motivation. Tujuan motivasi berkaitan dengan sikap dan perilaku civitas dalam menghadapi dan menanggapi hasil penjaminan mutu. Civitas akademik akan terdorong untuk melakukan perbaikan-perbaikan melihat hasil dari penjaminan mutu. Jika hasil penjaminan mutu belum menunjukkan hasil yang maksimal maka civitas akan terdorong untuk melakukan perbaikan. Jika hasil sudah menunjukkan kesempurnaan/ baik, mereka akan termotivasi untuk terus mempertahannya dengan melakukan praktik-praktik yang baik.

Control. Tujuan yang terakhir adalah kontrol/ pengawasan. Pelaksanaan penjaminan mutu akan memberikan umpan balik dari hasil pemeriksaan/ asesmennya kepada lembaga pendidikan. Hasil ini akan mejadi bahan evaluasi bagi penyelenggara dan kemudian melakukan perbaikan. Pengawasan akan dilakukan dan dipraktikkan yang bertujuan mengantisipasi hasil rekomadasi dari penjaminan mutu. Pengelola akan melakukan kontrol agar rekomendasi yang baik tetap dipertahankan dan dikembangan sedangkan rekomendasi perbaikan dipastikan tidak akan terjadi kembali. 
Implementasi tahapan sistem penjaminan mutu akan tercapai bila dukungan oleh top manajemen yang dilembaga pendidikan tinggi dan melakukan kerja sama dengan lembaga pendidikan lainnya. Kedua hal ini akan menjadikan ketercapaian efektivitas penjaminan mutu dapat diwujudkan (Seyfried \& Pohlenz, 2018). Selanjutnya untuk mempertahankan penjaminan mutu diperlukan konsep yang benar-benar dapat diterima oleh semua kalangan. Berbagai hasil penelitian menunjukkan bahwa budaya mutu menjadi solusi penting dalam peningkatan mutu lembaga pendidikan tinggi (Hildesheim \& Sonntag, 2020; Yingqiang \& Yongjian, 2016). Budaya mutu menekankan pentingnya peningkatan kualitas yang berkelanjutan, adanya sikap bersama, dan komitmen terhadap mutu (Dzimińska et al., 2018).

\section{KESIMPULAN}

Pendidikan tinggi akan memberikan dampak positif terhadap perkembangan suatu bangsa. Perkembangan informasi dan teknologi menuntut pendidikan tinggi harus terus beradaptasi dan berubah mengikutinya. Oleh sebab itu, lembaga pendidikan harus memiliki mutu yang baik. Pendidikan tinggi yang bermutu adalah yang mampu mencapai atau bahkan melampaui standar yang telah ditetapkan. Untuk mendapatkan pendidikan tinggi yang bermutu maka lembaga pendidikan perlu melakukan proses-proses penjaminan mutu baik secara internal maupun eksternal. Proses tersebut juga merupakan bahan evaluasi tentang apa yang belum dicapai dan yang harus pertahankan. Lembaga pendidikan perlu bekerjasama dengan seluruh stakeholder untuk dapat memberikan hasil terbaik.

\section{DAFTAR PUSTAKA}

Al-Alawi, Y., Al-Kaabi, D., Rashdan, S., \& Al-Khaleefa, L. (2009). Quality Assurance and Continuous Improvement: A Case Study of The University of Bahrain. Quality in Higher Education, 15(1), 61-69. https:/ / doi.org/10.1080/13538320902731575

Bernhard, A. (2012). Quality Assurance in an International Higher Education Area. Wiesbaden: VS Verlag für.

Cheung, J. C. M. (2015). Professionalism, Profession and Quality Assurance Practitioners in External Quality Assurance Agencies in Higher Education. Quality in Higher Education, 21(2), 151-170. https:/ / doi.org/10.1080/13538322.2015.1051795

Cheung, P. P. T., \& Tsui, C. B. S. (2010). Quality Assurance for All. Quality in Higher Education, 16(2), 169-171. https://doi.org/10.1080/13538322.2010.485723

Corengia, Á., Del Bello, J. C., Pita Carranza, M., \& Adrogué, C. (2014). Quality Assurance Systems of Higher Education - The Case of European Institutions: Origin, Evolution and Trends. Revista Gestão Universitária Na América Latina - GUAL, 7(3), 61-76. 
David L. Goetsch dan Stanley Davis. (2014). Quality Management: Introduction to Total Quality Management for Production (Pearson Ne). Edinburgh: Pearson.

Dill, D. (2010). Quality Assurance in Higher Education - Practices and Issues. International Encyclopedia of Education, 377-383. https:/ / doi.org/10.1016/B978-0-08-044894-7.00833-2

ENQA (ed.). (2009). tandards and Guidelines for Quality Assurance in the European Higher Education Area (3rd Ed). Helsinki: European Association for Quality Assurance in Higher Education.

Haapakorpi, A. (2011). Quality Assurance Processes in Finnish Universities: Direct and Indirect Outcomes and Organisational Conditions. Quality in Higher Education, $17(1)$ 69-81. https://doi.org/10.1080/13538322.2011.554311

Hildesheim, C., \& Sonntag, K. (2020). The Quality Culture Inventory: a Comprehensive Approach Towards Measuring Quality Culture in Higher Education. Studies in Higher Education, 45(4), 892-908. https://doi.org/10.1080/03075079.2019.1672639

Masrukhin. (2015). Metode Penelitian Kualitatif. Kudus: Media Ilmu Press.

Matei, L., \& Iwinska, J. (2016). Quality Assurance in Higher Education: a Practical Handbook. Budapest: Central European University.

Oakland, J. S. (2014). Total Quality Management and Operational Excellence:Text with cases (4th ed.). New York: Routledge.

Riset, K., \& Pendidikan Tinggi, D. (2016). Peraturan Menteri Riset, Teknologi, dan Pendidikan Tinggi Republik Indonesia Nomor 62 Tahun 2016 tentang Sistem Penjaminan Mutu Pendidikan Tinggi.

Rosa, M. J. (2014). The Academic Constituency. In M. J. Rosa \& A. Amaral (Eds.), Quality Assurance in Higher Education: Contemporary Debates (pp. 181-206). Basingstoke: Palgrave Macmillan.

Scharager Goldenberg, J. (2018). Quality in Higher Education: The View of Quality Assurance Managers in Chile. Quality in Higher Education, 24(2), 102-116. https:// doi.org/10.1080/13538322.2018.1488395

Seyfried, M., \& Pohlenz, P. (2018). Assessing Quality Assurance in Higher Education: Quality Managers' Perceptions of Effectiveness. European Journal of Higher Education, 8(3), 258-271. https://doi.org/10.1080/21568235.2018.1474777

Xiao, H., \& Zhang, X. (2017). Assuring Quality in Transnational Higher Education: A Case Study of Sino-Foreign Cooperation University in China. In D. E. Neubauer \& C. Gomes (Eds.), Quality Assurance in AsiaPacifi c Universities: Implementing Massifi cation in Higher Education (pp. 55-70). Cham: Palgrave Macmillan. 